\title{
Vaginal discharge: evaluation of syndromic management in Chhattisgarh Institute of Medical Sciences, Bilaspur, C.G.
}

\author{
Sangita Raman Jogi*
}

Department of Obstetrics \& Gynaecology, Chhattisgarh Institute of Medical Sciences, Bilaspur, CG, India

Received: 15 August 2015

Accepted: 18 September 2015

\author{
*Correspondence: \\ Dr. Sangita Raman Jogi, \\ E-mail: raman.jogi@yahoo.com
}

Copyright: (C) the author(s), publisher and licensee Medip Academy. This is an open-access article distributed under the terms of the Creative Commons Attribution Non-Commercial License, which permits unrestricted non-commercial use, distribution, and reproduction in any medium, provided the original work is properly cited.

\begin{abstract}
Background: Vaginal discharge is one of the most common problems faced by women. It may be physiological or pathological. Most of the time it caused by bacteria, fungi or parasites and many times these infections are sexually transmitted. Thus it is important to treat vaginal discharge as syndrome. Syndromic management is an inexpensive and effective method to treat vaginal discharge and no preliminary laboratory test are required. We have studied 300 patients attending OPD with complain of vaginal discharge to access the efficiency, acceptability and tolerance of one day combination kit therapy (azithromycin $1 \mathrm{~g}$, fluconazole $150 \mathrm{mg}$ and Secnidazole $2 \mathrm{~g}$ ).

Methods: Three hundred women were selected randomly with the complaint of vaginal discharge. They were examined thoroughly and advised to take one day kit therapy. Their partners were also advised to take same therapy. They were called after two weeks to know about their symptoms and for examination.

Results: Sixty percent women had excellent response for vaginal discharge, $75 \%$ women had excellent response for urinary symptoms and $77.3 \%$ women had excellent response for pruritus vulvae.

Conclusions: The combination kit therapy in vaginal discharge allows a simple and fast assured therapy, with high cure rate for vaginal discharge.
\end{abstract}

Keywords: Vaginal Discharge, Syndromic management, Combination kit therapy, STD

\section{INTRODUCTION}

Normal vaginal discharge is white, becoming yellowish on contact with air due to oxidation. Physiological discharge rise due to increased mucous production from the cervix in mid cycle pregnancy and women on oral contraceptive. The cause of vaginal discharge is bacterial vaginosis and cervicitis due to chlamydia and gonococci infection. Vaginal discharge is one of the most common and nagging problems faced by women.

About 20-25\% women who attended Gynecology outpatient department (OPD) complain vaginal discharge and leucorrhea. Though in few cases discharge may be physiological, increasing normal vaginal secretions, in more than $60 \%$ of cases it is because of infections of vagina or the cervix, caused by bacteria, fungi or parasitic agent. $^{1}$

Many a times these infections are sexually transmitted. Untreated or underrated (STD) is more prone to disease spread and runs a greater risk of contracting HIV. Vaginal discharge is often polymicrobial and treatment of only one or the most apparent cause may lead to a flare up and clinical manifestation of the other causes. Thus, it is important to treat vaginal discharge as a syndrome, than a single, most clinical apparent cause or disease. In syndromic management, diagnosis or treatment is not based on specific disease but rather on syndrome i.e. group of clinical findings in patient. No laboratory test is 
required and it is an inexpensive and effective method and the patient is treated empirically on antibiotics. Treatment is generally given for most of the diseases that could cause that syndrome. ${ }^{2}$

\section{METHODS}

Three hundred women who had the complain of vaginal discharge and attended Gynecology OPD from January 2014 to December 2014 in Chhattisgarh Institute of Medical Sciences, Bilaspur, were selected randomly. Their symptoms, menstrual and obstetric history, relevant past and personal history were documented and any history suggestive of STD in the woman and her husband was taken. Detailed gynecologic examinations were carried out and the severity and the type of discharge were noted. Women with severe type of vaginal discharge with or without chronic cervicitis were included. Pregnant and lactating women and women with history of drug allergy or those who had received any type of medication for vaginal discharge for last two weeks were excluded. All the patients were explained the type and design of study and due consent were taken. The couples were explained the sexual root of transmission and the importance of getting medication for both the partners together. Couple was given one day combination kit, containing: Fluconazole $(150 \mathrm{mg})$ - 1 Tablet, Azithromycin (1 gm) - 1 Tablet, Secnidazole (2 gm) - 2 Tablet. These patients (Husband and wife) were asked to take these tablets after meals on the same day. The couple was advised abstinence for fourteen days. On follow-up visits after two weeks, patients were asked about improvement of the symptoms in the percentage; tolerance of tablets in the form of adverse effect observed after the consumption.

\section{RESULTS}

This is a prospective study conducted in Chhattisgarh Institute of Medical Sciences, Bilaspur from January 2014 to December 2014. Out of 4466 gynaecological cases attending OPD, 300 cases presented with severe vaginal discharge which was $06.71 \%$ of total gynaecological registration.

According to Table 1 shows 120 cases were associated with urinary symptoms, 135 cases were associated with pruritus vulvae and 18 cases with pain abdomen. They were divided in four groups according to response to kit therapy. Patients relieved of $75-100 \%$ of symptoms, 50$75 \%, 25-50 \%$ and $<25 \%$ were categorized as excellent, moderate, minimal and no response, respectively (Table 2).

Table 3 shows that $180(60 \%)$ women had excellent response for vaginal discharge. Ninety six (32\%) and eight $(61 \%)$ women showed moderate and minimal response for vaginal discharge, respectively. Six (2\%) women had no response. Table 3 shows women relieved of their urinary symptoms. Out of 120 women, 90 (75\%),
$21(17.5 \%)$ and six (5\%) had excellent, moderate and minimal response, respectively. Three women had no response at all.

Table 1: Symptoms presented by the women.

\begin{tabular}{|ll|}
\hline Symptoms & Number of patients \\
\hline Vaginal discharge & 300 \\
\hline Urinary symptoms & 120 \\
\hline Pruritus vulvae & 135 \\
\hline Pain abdomen & 18 \\
\hline
\end{tabular}

Table 2: Response to Kit Therapy Grading.

\begin{tabular}{|ll|}
\hline Excellent & $75-100 \%$ \\
\hline Moderate & $50-75 \%$ \\
\hline Minimal & $25-50 \%$ \\
\hline No response & $<25 \%$ \\
\hline
\end{tabular}

Table 3 also shows response of women for symptoms of pruritus vulvae. Out of 135 women, 105(77.7\%), 24 $(17.7 \%)$, three $(2.2 \%)$ had excellent, moderate and minimal response, respectively. Pain abdomen was completely relieved in $61.3 \%$ women (Table 4). Most common adverse effects of kit therapy were anorexia (20\%) metallic taste (18\%) nausea (19\%), vomiting (6\%) epigastric pain $(15 \%)$ and headache $(4 \%)$. No women discontinued the therapy because of side effects (Table 5).

\section{DISCUSSION}

The commonest presentation of STD is vaginal discharge. Amongst women, the common causes of vaginal discharge are trichomonal vaginitis, candidial vaginitis and bacterial vaginiosis. However, cervicitis caused by gonorrhea and Chlamydia trachomatis also cause vaginal discharge, although cervicitis causing vaginal discharge is less common, it is a more serious cause as it may lead to pelvic inflammatory disease and its related complications. More often, vaginal infection is polymicrobial in nature. ${ }^{1}$

Untreated STD is more prone to disease spread and runs a higher risk of contracting HIV; STDs increases the risk of HIV. ${ }^{2}$ The diagnosis and subsequent treatment often depends on clinical and laboratory diagnosis. In vaginal discharge, clinical diagnosis is often inaccurate and has limited value. ${ }^{3}$ The final diagnosis depends upon laboratory diagnosis which is time-consuming, expensive and many a time, not available.

In 1998, WHO introduced the concept of syndromic management. In syndromic management, treatment is based not on specific disease identified by testing but on syndrome which is a group of clinical findings. Treatment is generally given for all or least for most commonly seen diseases that could cause that syndrome. To be effective, syndromic approach mostly considered 
the data on prevalence of STD in a given area, antibiotic resistance and drug availability. As it is important to assess risk, which is helpful to decide, whether to treat cervicitis, which is likely to be associated with vaginitis. Drug selected for syndromic management should have high efficacy, few side effects, cost-effective, should be orally administrable and preferably given as a single dose to increase acceptance and compliance. Syndromic management has many advantages over conventional methods. It decreases dependence on laboratory tests in resource-limited countries like India where laboratory testing may be too expensive and are often unavailable. Even where laboratory diagnosis is available, it is timeconsuming and often does not correlate with clinical findings.

Table 3: Response in percentage.

\begin{tabular}{|llllll|}
\hline Symptoms & Number & Excellent \% & Moderate \% & Minimal \% & No response \% \\
\hline Vaginal Discharge & 300 & $180(60 \%)$ & $96(36 \%)$ & $8(6 \%)$ & $6(2 \%)$ \\
\hline Urinary Symptoms & 120 & $90(75 \%)$ & $21(17.5 \%)$ & $6(5 \%)$ & $3(2.5 \%)$ \\
\hline Pruritis Vulvae & 135 & $105(77.7 \%)$ & $24(17.7 \%)$ & $3(2.2 \%)$ & $3(2.2 \%)$ \\
\hline
\end{tabular}

Table 4: Relief of pain abdomen.

\begin{tabular}{|c|c|c|c|c|}
\hline Symptom & Number & Complete relief & Partial relief & No response \\
\hline Pain abdomen & 18 & $61.1 \%$ & $4(22.2 \%)$ & $3(16.6 \%)$ \\
\hline
\end{tabular}

Syndromic approach greatly simplifies complete administrative process with advanced medical -skills or experience. In developing countries like ours, it significantly expands the pool of healthcare providers thus reducing the prevalence of such diseases. The most important benefit of syndromic management is that treatment begins immediately.

Patient acceptance and compliance is good. In our study, few women experienced some adverse effect but no women discontinued the therapy.

Table 5: Adverse effect of kit therapy.

\begin{tabular}{|lll|}
\hline Symptoms & Number of patient & $\%$ \\
\hline Anorexia & 60 & $20 \%$ \\
\hline Metallic taste & 54 & $18 \%$ \\
\hline Nausea & 57 & $19 \%$ \\
\hline Vomiting & 18 & $6 \%$ \\
\hline Epigastric pain & 45 & $15 \%$ \\
\hline Headache & 12 & $4 \%$ \\
\hline Allergic rash & Nil & Nil \\
\hline $\begin{array}{l}\text { Discontinuation of } \\
\text { medicine }\end{array}$ & Nil & Nil \\
\hline
\end{tabular}

The most commonly encountered etiologies of vaginal discharge are trichomoniasis, moniliasis, bacterial vaginosis, chlamydial infection and gonorrhea. Therefore syndromic management should be directed against all these diseases. Both trichomoniasis and bacterial vaginosis can be treated with metronidazole. In the past five decades, metronidazole was the first treatment.
Now there is increased resistance to metronidazole for trichomoniasis, secnidazole single dose $2 \mathrm{~g}$ has better tolerability and patient compliance. It has larger half-life and a large duration of action with less side effects. A single $2 \mathrm{~g}$ dose is very effective in bacterial vaginosis and trichomoniasis. $^{4,5}$

Vaginal candidiasis is managed with vaginal tablets like clotrimazole or miconazole. This topical treatment is often inconvenient and unacceptable due to various cultures, religious and social factors. Oral fluconazole has increased acceptance and is the only drug which is very effective and well tolerated. ${ }^{6}$

Chlamydia and gonorrhea are routinely treated with tetracycline which is given in multiple doses. This led to poor patient compliance and missed doses leading to relapse. Azithromycin $1 \mathrm{~g}$ single dose is very effective against chlamydia and gonorrhea. ${ }^{7}$ In our study, we got excellent response for vaginal discharge in $60 \%$ of cases. Pepin and Sobela et al observed complete relief of vaginal discharge with syndromic management in $66 \%{ }^{8}$

Bornstein et al studied effect of combination therapy versus cotrimazole therapy on vaginitis. ${ }^{9}$ They enrolled 165 patients out of which 84 were given combination therapy and 81 were on cotrimazole therapy. They found more effective response in combination therapy (99\%).

Samina et al observed effect of combination therapy in chronic vaginal discharge with $56 \%$ improvement after first course and $84 \%$ improvement after second course. ${ }^{10}$

Kissinger et al studied effect of single versus 7 days dose of metronidazole for treatment of Trichomonas vaginalis 
among 270 HIV positive patients. ${ }^{11}$ They found 7 days treatment is more effective in HIV positive patients.

Onyekonwn et al observed 195 patients of vaginal symptoms and found $36 \%$ relief by single day therapy. ${ }^{12}$

Milsana et al studied 242 women in South Africa who were high risk for STI and genital infection and had clinical evident discharge, they found 25 patients $(12.3 \%)$ had positive laboratory test for diagnosis of vaginitis. They found syndromic treatment at initial stage of disease had better response. ${ }^{13}$ Similarly A Lewis et al studied 1232 cases of vaginal discharge and they found $33.8 \%$ reduction in vaginitis. ${ }^{14}$

Pamer et al studied prevalence of sexually transmitted infection in response to syndromic treatment among 415 married women of rural area of Mumbai. They found after syndromic treatment symptomatic, clinical and laboratory prevalence has been reduced for $39 \%$ to $14 \%$, $323 \%$ to $9 \%$ and $26 \%$ to $6 \%$ respectively. ${ }^{15}$

Sena et al also found that syndromic or single dose therapy is effective and cost effective management for initial stage of illness. ${ }^{16}$

Alam et al studied knowledge of 225 rural Medical practitioners about treatment of vaginitis, STI and training given to them for proper drugs and doses. Combination kit was advised to them to use as first line treatment for white discharge. ${ }^{17}$

Maladkar et al Studied 495 patients of mixed vaginal discharge and found $99.2 \%$ reduction in vaginal burning and irritation by 7 days vaginal pesseries and combination single dose oral therapy. ${ }^{18}$

Combination kits are cheaper and effective when given in single day dose orally with efficacy of 95 to $98 \%$. Single day dose allows good compliance, treatment at first visit thus preventing the speed of sexually transmitted disease and HIV. It has been observed that immediate complete treatment prevent secondary complications.

\section{CONCLUSIONS}

Combination kit therapy in syndromic management of vaginal discharge is cheaper, effective and is given in single doses, with excellent efficacy. It allows good compliance, complete treatment at first onset, thus prevent STD transmission and HIV transmission.

\section{Funding: No funding sources}

Conflict of interest: None declared

Ethical approval: The study was approved by the Institutional Ethics Committee

\section{REFERENCES}

1. World Health Organization. Guideline for the management of sexually transmitted infection. Geneva. WHO, 2001.

2. Chesson HW, Pinkerton SD. sexually transmitted diseases and the increased risk for HIV transmission: implications forcost-effectiveness analyses of sexually transmitted disease prevention interventions. J Acquir Immune Defic Syndr. 2000;24(1):48-56.

3. Karaca M, Bayram A, Kocoglu ME, Gocmen A, Eksi F. Comparison of clinical diagnosis and microbiological test results invaginal infections. Clin Exp Obstet Gynecol. 2005;32(3):172-4.

4. Gil lis JC, Wiseman LR. Secnidazole. A review of its antimicrobial activity, pharmacokinetic properties and therapeutic use in the management of protozoal infections and bacterial vaginosis Drugs. 1996;51(4):621-38.

5. Rossignol JF, Maisonneuve H, Cho YW. Nitroimidazoles in the treatment of trichomoniasis, giardiasis, and amebiasis. Int J Clin Pharmacol Ther Toxicol. 1984;22(2):63-72.

6. A comparison of single-dose oral fluconazole with 3day intravaginal clotrimazole in the treatment of vaginal candidiasis. Report of an international multicenter trial. $\mathrm{Br} \mathrm{J}$ Obstet Gynaecol. 1989;96(2):226-32.

7. Pitsouni E, lavazzo C, A Thanasiou S, Falagas ME. Single-dose azithromycin versus erythromycin or amoxicillin for Chlamydia trachomatis infection during pregnancy: a meta-analysis of randomized controlled trials. Int $\mathbf{J}$ Antimicrob Agents. 2007;30(3):213-21.

8. Pepin J, Sobela F, Khonde N, Agyarko-Poku T, Diakite S, Deslandes S, et al. The syndromic management of vaginal discharge using single-dose treatments: a randomized controlled trial in West Africa. Bull World Health Organ. 2006;84(9):72938.

9. Jacob Bornstein, Doron Zafate. A universal combination treatment for vaginitis, A randomized controlled trail. Gynecol Obstel Invest. 2008;65:195200.

10. Sabir S, Hussan L. Outcome of syndromic management in case of chronic vaginal discharge. JPM. 2010;24(03):234-8.

11. Kissinger $P$, Mena LA. Randomized treatment trial ,single versus 7 days dose of Metronidazole for treatment of Trichomonas vaginalis among HIV infected women. J Acquir immune defic syndr. 2010;55(5):567-71.

12. Onyekown CL, Olumide Y, Oresanya F. Vaginal Discharge: Etiological Agents and evaluation of Syndromic management in Lagos. Niger $\mathbf{J}$ Med. 2011;20(1):155-62.

13. Milsana K, Naicker N, Werner L, Roberts L, et al. Symptomatic vaginal discharge in a poor predictor of sexually transmitted infections and genital tract 
inflammation in high risk women in South Africa. J Infect Dis. 2012;206(1):6-14.

14. Lewis DA, Kimberly M, Frans R. Trends and association of trichomonad vaginalis infection women with genital discharge syndrome in Johannesburg South Africa. Sex Trans Infect. 2013;10:1136.

15. Parmar MT, Harsha M. A study of Prevalence of sexually transmitted infection and response to syndromic treatment among married women of reproductive age group in rural area of Parol primary health centre under Thane district. Global Journal of Medicine and Public Health. 2013;2(2):480-4.

16. Sena AC, Bachman LH, Hobb M. Persistant and recurrent Trichomonas Vaginalis infection: Epidemiology, treatment and management consideration. Expert Rev Anti Infective therapy. 2014;12(6):673-85.

17. Nazmul A, Malay K, Kristensen S. Knowledge and skill for management of sexually transmitted infection by rural medical practitioners in Bangladesh. Open Journal of Preventive medicine. 2015;5:151-8.

18. Maladkar M, Tekchandani C, Dave U. Clindamycine, clotrimazole and Tinidazole in Mixed vaginosis-A real world clinical experience.Journal of Gynaecology and Obstetrics. 2015;3(3):49-54.

Cite this article as: Jogi SR. Vaginal Discharge: Evaluation of Syndromic Management in Chhattisgarh Institute of Medical Sciences, Bilaspur, CG. Int J Reprod Contracept Obstet Gynecol 2015;4:1534-8. 